\title{
THE OUTCOME OF STRABISMUS SURGERY IN CHILDHOOD EXOTROPIA
}

\author{
J. M. KEENAN and H. E. WILLSHAW \\ Birmingham
}

\begin{abstract}
SUMMARY
The results of squint surgery in 42 children with primary, non-paralytic, childhood exotropia are analysed. A 'favourable outcome', defined as a final alignment for near and distance within \pm 10 dioptres of straight, or within \pm 20 dioptres of straight with evidence of binocular single vision, was achieved in $39(93 \%)$ children. The factors affecting the final outcome are discussed, including age of onset, age at the time of surgery, preoperative and post-operative amblyopia, refractive error, anisometropia, the surgical procedures used, and postoperative ocular alignment.
\end{abstract}

Exotropia in childhood may be primary, secondary, consecutive or paralytic. ${ }^{1}$ Primary childhood exotropia may be constant, when the exotropia is manifest for both near and distance, or intermittent, when the exotropia is manifest for either near or distance. Intermittent distance exotropia may be either true or simulated depending on the amount of exophoria controlled for near by accommodation and fusional forces. ${ }^{2}$

We reviewed children who underwent strabismus surgery for primary childhood exotropia at the Birmingham Children's Hospital, in order to determine the results achieved, to identify the factors associated with favourable and less favourable outcomes, and to consider this information in the planning of future surgery for this condition.

\section{PATIENTS AND METHODS}

The case notes of consecutive patients undergoing surgery for childhood exotropia at the Birmingham Children's Hospital in the 5 year period between January 1982 and December 1986 were reviewed. Any child with paralytic or consecutive exotropia, neurological disorder, ocular pathology, or a post-operative follow-up period of less than 24 months, was excluded. Information was obtained from the pre-operative examination, and from examin-

From: Department of Paediatric Ophthalmology, Birmingham Children's Hospital, Ladywood Middleway, Birmingham B16 8ET, UK.

Correspondence to: J. M. Keenan, FRCS, FRCOphth, Moorfields Eye Hospital, City Road, London EC1V 2PD, UK. ations at 2 weeks, at 3-6 months, and at yearly intervals thereafter until discharge.

True distance exotropia was defined as an exotropia at distance which exceeded the exophoria at near by more than 10 dioptres; simulated distance exotropia was considered present when the difference was 10 dioptres or less. ${ }^{3}$

Amblyopia was defined as a difference of two lines or more between the monocular visual acuities. Anisometropia was defined as a spherical or cylindrical difference of greater than 1.0 dioptre between the two eyes. ${ }^{4}$ All refractions were undertaken under cycloplegia using either cyclopentolate or atropine. Binocular single vision was assessed using tests of motor and sensory fusion as described in a previous publication, and one or more of these tests of motor or sensory fusion were used at each pre-operative or post-operative examination. ${ }^{5}$

A 'favourable outcome' was defined as a final alignment for near and distance within \pm 10 dioptres of straight, or within \pm 20 dioptres of straight with evidence of binocular single vision.

Statistical analysis was performed using medians and the non-parametric Mann-Whitney test for comparing continuous variables, and the chi-squared test with Yates' correction or Fisher's exact test for categorical data.

\section{RESULTS}

The inclusion criteria were fulfilled by 42 patients, comprising $11(26.2 \%)$ with constant extropia, $17(40.5 \%)$ with simulated distance exotropia, and $14(33.3 \%)$ with true distance exotropia. No patient underwent surgery for the near type of intermittent exotropia. The results are presented for each of these categories.

\section{Constant Exotropia}

There was evidence of pre-operative binocular single vision in 6 of the 11 children (54.5\%) with constant exotropia. The median age of onset was 16 months, and the median age at surgery 50 months. Pre-operative amblyopia treatment was required for 4 children $(36.4 \%)$, of whom 3 remained amblyopic at the time of surgery. The 
Table I. Clinical characteristics of the individual groups of childhood exotropia

\begin{tabular}{lccc}
\hline & $\begin{array}{c}\text { Constant } \\
\text { exotropia }\end{array}$ & $\begin{array}{c}\text { Simulated distance } \\
\text { exotropia }\end{array}$ & $\begin{array}{c}\text { True distance } \\
\text { exotropia }\end{array}$ \\
\hline Pre-operative BSV & $6(54.5 \%)$ & $17(100 \%)$ & $14(100 \%)$ \\
Pre-operative amblyopia treatment & $4(36.4 \%)$ & $2(11.8 \%)$ & $5(35.7 \%)$ \\
Anisometropia & $3(27.3 \%)$ & 0 & $2(14.3 \%)$ \\
Re-operation & $4(36.4 \%)$ & $4(23.5 \%)$ & $1 \%(7.1 \%)$ \\
Median follow-up (months) & 54 & 35 & 35.5 \\
Favourable outcome & $8(72.7 \%)$ & $17(100 \%)$ & $14(100 \%)$ \\
Total & $11(100 \%)$ & $17(100 \%)$ & $14(100 \%)$ \\
\hline
\end{tabular}

$\mathrm{BSV}$, binocular single vision.

median refractive error was +2.25 dioptres. Anisometropia was present in 3 children, and 1 child had inferior oblique overaction.

Unilateral lateral rectus recession/medial rectus resection procedures were performed for 10 of the 11 children (90.9\%); simultaneous inferior oblique surgery was combined in 1 of these children. A lateral rectus recession/ medial rectus resection combined with a contralateral lateral rectus recession was performed for 1 child. Further surgery was required for 4 children $(36.4 \%)$, all of whom underwent a contralateral lateral rectus recession/medial rectus resection for residual exotropia. Post-operative amblyopia treatment was required in 2 children, of whom 1 remained amblyopic at final outcome. The median follow-up was 54 months, and a favourable outcome was achieved in 8 of the 11 children $(72.7 \%)$ in this group.

\section{Simulated Distance Exotropia}

There was evidence of pre-operative binocular single vision in all of the 17 children with simulated distance exotropia. The median age of onset was 44 months, and the median age at surgery 68 months. Pre-operative amblyopia treatment was required for 2 children (11.8\%), neither of whom remained amblyopic at the time of surgery. The median refractive error was +2.5 dioptres. Inferior oblique overaction was present in 1 child, and none of the children were anisometropic.

Unilateral lateral rectus recession/medial rectus resection procedures were performed for all children in this group. Further surgery was required for 4 children $(23.5 \%)$, all of whom underwent a contralateral lateral rectus recession/medial rectus resection for residual exotropia. Post-operative amblyopia treatment was required in 1 child, and none of the children was amblyopic at final outcome. The median follow-up was 35 months, and a favourable outcome was achieved for the total group.

\section{True Distance Exotropia}

There was evidence of pre-operative binocular single vision in all of the 14 children with true distance exotropia. The median age of onset was 23 months, and the median age at surgery 66.5 months. Pre-operative amblyopia treatment was required for 5 children $(35.7 \%)$, of whom 2 remained amblyopic at the time of surgery. The median refractive error was +2.0 dioptres. Anisometropia was present in 2 children, and none of the children showed inferior oblique overaction.

Unilateral lateral rectus recession/medial rectus resection procedures were performed for all children in this group. further surgery was required for 1 child (7.1\%), who underwent a contralateral lateral rectus recession/ medial rectus resection for residual exotropia. Post-operative amblyopia treatment was required for 2 children, and 1 remained amblyopic at final outcome. The median follow up was 35.5 months, and a favourable outcome was achieved for the total group.

A summary of the results is presented in Table I. Each group was then analysed to determine the indicators of a favourable or non-favourable outcome.

\section{ANALYSIS \\ Pre-operative Factors (Table II)}

\section{Age of Onset}

The median age of onset in constant exotropia was 16 months (range 0-124 months). An onset prior to 12 months of age was present in 3 of the 11 children (27.3\%), and after 12 months in 8 children $(72.7 \%)$. A favourable outcome was present in 2 of the 3 children $(66.7 \%)$ in the early-onset group, and in 6 of the 8 children (75\%) in the later-onset group.

Table II. Pre-operative characteristics of the individual groups of childhood exotropia

\begin{tabular}{|c|c|c|c|}
\hline & $\begin{array}{l}\text { Constant } \\
\text { exotropia }\end{array}$ & $\begin{array}{c}\text { Simulated distance } \\
\text { exotropia }\end{array}$ & $\begin{array}{l}\text { True distance } \\
\text { exotropia }\end{array}$ \\
\hline Median age of onset (months) & 16 & 44 & 23 \\
\hline Median age at surgery (months) & 50 & 68 & 66.5 \\
\hline Median pre-operative duration of strabismus (months) & 29 & 35 & 31 \\
\hline Pre-operative BSV & $6(54.5 \%)$ & $17(100 \%)$ & $14(100 \%)$ \\
\hline Pre-operative amblyopia treatment & $4(36.4 \%)$ & $2(11.8 \%)$ & $5 \quad(35.7 \%)$ \\
\hline Amblyopia at the time of surgery & $3(27.3 \%)$ & 0 & $2(14.3 \%)$ \\
\hline Median pre-operative squint angle (dioptres) & -50 & -30 & -40 \\
\hline Total & $11(100 \%)$ & $17(100 \%)$ & $14(100 \%)$ \\
\hline
\end{tabular}


Table III. Operative characteristics of the individual groups of childhood exotropia

\begin{tabular}{lccc}
\hline & $\begin{array}{c}\text { Constant } \\
\text { exotropia }\end{array}$ & $\begin{array}{c}\text { Simulated distance } \\
\text { exotropia }\end{array}$ & $\begin{array}{c}\text { True distance } \\
\text { exotropia }\end{array}$ \\
\hline Unilateral LR recession/MR resection & $10(90.1 \%)$ & $17(100 \%)$ & $14(100 \%)$ \\
LR recession/MR resection + contralateral LR recession & 1 & 0 & 0 \\
Total & $11(100 \%)$ & $17(100 \%)$ & $14(100 \%)$ \\
\hline
\end{tabular}

$\mathrm{LR}$, lateral rectus; $\mathrm{MR}$, medial rectus.

In simulated distance exotropia the median age of onset was 44 months (range 8-79 months), and in true distance exotropia the median age of onset was 23 months (range 4-144 months).

\section{Age at Surgery}

The median age at strabismus surgery in constant exotropia was 50 months. Surgery was undertaken in 5 of the 11 children $(45.5 \%)$ before their fourth birthday, and in 6 children $(54.5 \%)$ after this time. A favourable outcome was achieved in 4 of the 5 children $(80 \%)$ in the earlysurgery group, and in 4 of the 6 children $(66.7 \%)$ in the later group.

In simulated distance exotropia the median age at strabmismus surgery was 68 months. Surgery was undertaken before the fourth birthday in 1 of the 17 children (5.9\%), and a favourable outcome was present in all children.

In true distance exotropia the median age at strabismus surgery was 66.5 months. Surgery was undertaken in 4 of the 14 children $(28.6 \%)$ before their fourth birthday, and in 10 children $(71.4 \%)$ after this time. A favourable outcome was present in all children.

\section{Duration of Strabismus}

The median interval between onset of strabismus and surgery was 29 months (range 13-70 months) in constant exotropia, 35 months (range 12-84 months) in simulated distance exotropia, and 31 months (range 14-96 months) in true distance exotropia.

\section{Pre-operative Binocular Single Vision}

Pre-operative binocular single vision was present in 6 of the 11 children $(54.5 \%)$ with constant exotropia, and in all children with simulated and true distance exotropia.

\section{Pre-operative Amblyopia}

Pre-operative amblyopia treatment was required for 4 of 11 children $(36.4 \%)$ with constant exotropia, 2 of 17 children $(11.8 \%)$ with simulated distance exotropia, and 5 of 14 children (35.7\%) with true distance exotropia. Amblyopia persisted at the time of surgery in 3 of 11 children $(27.3 \%)$ with constant exotropia, in 2 of 14 children $(14.3 \%)$ with true distance exotropia, and was successfully treated in the 2 children with simulated distance exotropia.

\section{Pre-operative Squint Angle}

The median pre-operative squint angle was -50 dioptres (range -20 to -50 dioptres) in constant exotropia, -30 dioptres (range -15 to -55 dioptres) in' simulated distance exotropia, and -40 dioptres (range -20 to -50 dioptres) in true distance exotropia.

\section{Operative Factors (Table III)}

\section{Surgical Procedures}

A unilateral lateral rectus recession/medial rectus resection, with or without combined inferior oblique surgery, was performed as the initial surgery in 41 of the 42 children $(97.6 \%)$ in the total group. One child, with constant exotropia, underwent a simultaneous contralateral lateral rectus recession.

Table IV. Post-operative characteristics of the individual groups of childhood exotropia

\begin{tabular}{|c|c|c|c|}
\hline & $\begin{array}{l}\text { Constant } \\
\text { exotropia }\end{array}$ & $\begin{array}{c}\text { Simulated distance } \\
\text { exotropia }\end{array}$ & $\begin{array}{c}\text { True distance } \\
\text { exotropia }\end{array}$ \\
\hline $\begin{array}{l}\text { Within } \pm 15 \text { dioptres of straight } \\
\text { Consecutive esotropia }>+15 \text { dioptres } \\
\text { Residual exotropia }>-15 \text { dioptres }\end{array}$ & $\begin{array}{ll}3 & (27.3 \%) \\
0 & \\
8 & (72.7 \%)\end{array}$ & $\begin{array}{rr}14 & (82.4 \%) \\
2 & (11.8 \%) \\
1 & (5.9 \%)\end{array}$ & $\begin{array}{rr}10 & (71.4 \%) \\
3 & (21.4 \%) \\
1 & (7.1 \%)\end{array}$ \\
\hline $\begin{array}{l}\text { Post-operative alignment at } 3-6 \text { month } \\
\text { Within } \pm 15 \text { dioptres of straight } \\
\text { Consecutive esotropia }>+15 \text { dioptres } \\
\text { Residual exotropia }>-15 \text { dioptres } \\
\text { Further surgery }\end{array}$ & $\begin{array}{ll}7 & (63.6 \%) \\
0 & \\
4 & (36.4 \%) \\
4 & (36.4 \%)\end{array}$ & $\begin{array}{rr}12 & (70.6 \%) \\
2 & (11.8 \%) \\
3 & (17.6 \%) \\
4 & (23.5 \%)\end{array}$ & $\begin{array}{rr}12 & (85.7 \%) \\
0 & \\
2 & (14.3 \%) \\
1 & (7.1 \%)\end{array}$ \\
\hline $\begin{array}{l}\text { Post-operative BSV } \\
\text { Motor fusion } \\
\text { Sensory fusion } \\
\text { None present } \\
\text { Post-operative amblyopia treatment } \\
\text { Amblyopia at final outcome }\end{array}$ & $\begin{array}{ll}3 & (27.3 \%) \\
3 & (27.3 \%) \\
5 & (45.5 \%) \\
3 & (27.3 \%) \\
2 & (18.2 \%)\end{array}$ & $\begin{array}{rr}16 & (94.1 \%) \\
1 & (5.9 \%) \\
0 & \\
1 & (5.9 \%) \\
0 & \end{array}$ & $\begin{array}{rr}12 & (85.7 \%) \\
1 & (7.1 \%) \\
1 & (7.1 \%) \\
4 & (28.6 \%) \\
3 & (21.4 \%)\end{array}$ \\
\hline Total & $11(100 \%)$ & $17(100 \%)$ & $14(100 \%)$ \\
\hline
\end{tabular}




\section{Amount of Surgery}

The amount of surgery performed ranged from a lateral rectus recession of $3 \mathrm{~mm}$ and a medial rectus resection of $3 \mathrm{~mm}$ for a pre-operative squint angle of -15 dioptres, to a lateral rectus recession of $8 \mathrm{~mm}$ and a medial rectus resection of $6 \mathrm{~mm}$ undertaken in 4 children with pre-operative squint angles of -50 to -55 dioptres.

\section{Post-operative Factors (Table IV)}

\section{Post-operative Alignment}

In constant exotropia, 3 of the 11 children (27.3\%) were aligned within \pm 15 dioptres of straight at the 2 week postoperative examination and 8 children $(72.7 \%)$ had a residual exotropia of greater than 15 dioptres. At 3-6 months post-operatively 7 of the 11 children $(63.6 \%)$ were aligned to within \pm 15 dioptres of straight, and 4 children $(36.4 \%)$ had a residual exotropia of greater than 15 dioptres. A favourable outcome was achieved in 6 of the 7 children $(85.7 \%)$ aligned within \pm 15 dioptres at 3-6 months postoperatively, and in only 2 of the 4 children (50\%) not achieving this alignment. At 3-6 months the post-operative alignment was greater than \pm 10 dioptres of straight in 10 of the 11 children ( $90.9 \%$ ), and was greater than \pm 20 dioptres of straight in 1 child $(9.1 \%)$.

In simulated distance exotropia, 14 of the 17 children $(82.4 \%)$ were aligned within \pm 15 dioptres of straight at the 2 week post-operative examination, 2 children $(11.8 \%)$ had a consecutive esotropia of greater than 15 dioptres, and 1 child (5.9\%) had a residual exotropia of greater than 15 dioptres. At 3-6 months post-operatively 12 of the 17 children $(70.6 \%)$ were aligned to within \pm 15 dioptres of straight, 2 children $(11.8 \%)$ had a consecutive esotropia of greater than 15 dioptres, and 3 children $(17.6 \%)$ had a residual exotropia of greater than 15 dioptres. A favourable outcome was achieved in all children. At 3-6 months the post-operative alignment was greater than \pm 10 dioptres of straight in 10 of the 17 children $(58.8 \%)$, and was greater than \pm 20 dioptres of straight in 2 children $(11.8 \%)$.

In true distance exotropia, 10 of the 14 children $(71.4 \%)$ were aligned within \pm 15 dioptres of straight at the 2 week post-operative examination, 3 children $(21.4 \%)$ had a consecutive esotropia of greater than 15 dioptres, and 1 child (7.1\%) had a residual exotropia of greater than 15 dioptres. At 3-6 months post-operatively 12 of the 14 children $(85.7 \%)$ were aligned to within \pm 15 dioptres of straight, and 2 children (14.3\%) had a residual exotropia of greater than 15 dioptres. A favourable outcome was achieved in all children. At 3-6 months the post-operative alignment was greater than \pm 10 dioptres of straight in 3 of the 14 children $(21.4 \%$ ), and was greater than \pm 20 dioptres of straight in 2 children (14.3\%).

A consecutive esotropia was present in 16 of the 42 children $(38.1 \%)$ at the first post-operative visit, comprising 1 of the 11 children $(9.1 \%)$ with constant exotropia, 5 of the 17 children $(29.4 \%)$ with simulated distance exotropia, and 10 of the 14 children $(71.4 \%)$ with true distance exo- tropia. A consecutive esotropia for near and distance was present in 11 of these 16 children, an esotropia for near and an exotropia for distance was present in 4 children, and 1 child was straight for near with an esotropia for distance. At 3-6 months post-operatively an esotropia for near or distance was present in 7 of the 16 children $(43.8 \%)$, and at final outcome 6 of these 7 children remained esotropic for near or distance.

\section{Further Surgery}

Further surgery for residual exotropia was required for 4 of the 11 children $(36.4 \%)$ with constant exotropia. A post-operative squint angle at 3-6 months within \pm 15 dioptres of straight was present in 2 of these children, and both obtained a favourable outcome. A post-operative squint angle at 3-6 months of greater than \pm 15 dioptres of straight was present in the other 2 children, 1 of whom obtained a favourable outcome.

Further surgery for residual exotropia was required for 4 of the 17 children $(23.5 \%)$ with simulated distance exotropia. A post-operative squint angle at 3-6 months was within \pm 15 dioptres of straight in 2 children, and was greater than this in 2 children. A favourable outcome was achieved in all 4 children.

Further surgery for residual exotropia was required for 1 of the 14 children $(7.1 \%)$ with true distance exotropia. A post-operative squint angle at 3-6 months of greater than \pm 15 dioptres of straight was present in this child, and a favourable outcome was achieved.

No surgery was performed to correct post-operative consecutive esotropia.

\section{Post-operative Binocular Single Vision}

At final outcome, 3 of 11 children (27.3\%) with constant exotropia showed grades of sensory fusion, 3 children (27.3\%) showed motor fusion, and there was no evidence of binocular single vision in 5 children $(45.5 \%)$. In simulated distance exotropia 16 of the 17 children (94.1\%) showed grades of sensory fusion, and motor fusion was present in 1 child (5.9\%). In true distance exotropia 12 of the 14 children $(85.7 \%)$ showed grades of sensory fusion, motor fusion was present in 1 child $(7.1 \%)$, and 1 child (7.1\%) showed no evidence of binocular single vision.

\section{Post-operative Amblyopia}

Post-operative occlusion was required for 3 of the 11 children $(27.3 \%)$ with constant exotropia, and amblyopia persisted in 2 children, neither of whom achieved a favourable outcome. In simulated distance exotropia postoperative occlusion was required for 1 of the 17 children (5.9\%), and no children remained amblyopic at final outcome. In true distance exotropia post-operative occlusion was required for 4 of the 10 children (28.6\%), and amblyopia persisted in 3 children, all of whom obtained a favourable outcome.

\section{DISCUSSION}

The type of exotropia present provides an initial indication 
of the likelihood of achieving a favourable outcome. Children with intermittent exotropia usually maintain some form of binocular single vision, ${ }^{6}$ and may be expected to achieve more favourable results following strabismus surgery than those children with constant or infantile exotropia. $^{7-9}$ All children with true or simulated distance exotropia in this study achieved a favourable outcome, compared with a favourable outcome achieved in 8 of the 11 children $(72.7 \%)$ with constant exotropia. The children with true or simulated distance exotropia had better grades of pre-operative binocular single vision, and also achieved better grades of post-operative binocular single vision than those children with constant exotropia.

The median age of onset in our study was younger for constant exotropia (16 months) than for simulated distance (44 months) or true distance exotropia (23 months). The earlier onset recorded for children with constant exotropia may be a true feature of this condition, or it may in part be because constant exotropia is more noticeable than when the condition is intermittent. Infantile exotropia, with onset of strabismus during the first year of life, has been compared to congenital esotropia, as both are characterised by constant, large angle deviations, representing a barrier to the development of binocular single vision. ${ }^{9} \mathrm{~A}$ favourable outcome was achieved in constant exotropia in 2 of 3 children $(66.7 \%)$ with onset in the first year of life, and in 6 of the 8 children $(75 \%)$ with onset after that time; a favourable outcome was achieved in all children with simulated or true distance exotropia regardless of the age of onset.

The age at which surgery should be performed for childhood exotropia has been a subject of debate. The proposed advantages of early surgery include preventing the establishment of sensory changes, minimising the reinforcement of the habit of squinting, ${ }^{10}$ and the demonstration of good post-operative results following early strabismus surgery. ${ }^{11}$ The proposed advantages for later surgery are that it allows progress of the deviation to be monitored, that more accurate measurements of the deviation can be made, that consecutive esotropia is less likely to occur, ${ }^{12}$ and that some studies show no difference in final outcome with later surgery. ${ }^{7}$ No significant difference was found in our study in relation to the age at strabismus surgery: a favourable outcome was achieved in 9 of 10 children (90\%) undergoing strabismus surgery before their fourth birthday, and in 30 of 32 children $(93.8 \%)$ undergoing strabismus surgery after that time.

It is important to decide before strabismus surgery what post-operative alignment is being aimed for in childhood exotropia, and the likelihood that this alignment will remain stable. The post-operative alignment at 2 weeks provides the best estimation of the mechanical outcome of the strabismus surgery performed, and this is subsequently modified by other factors. Our results show that 27 of 32 children $(84.4 \%)$ aligned within \pm 15 dioptres of straight at 2 weeks post-operatively maintained this alignment at the 3-6 months examination, and that alignment within \pm 15 dioptres of straight at 3-6 months post-oper- atively correlates well with the achievement of a favourable outcome.

We have previously demonstrated that for childhood esotropia and congenital esotropia achieving a post-operative alignment within \pm 10 dioptres or \pm 15 dioptres of straight, respectively, at 3-6 months was associated with obtaining a favourable outcome. ${ }^{13,14}$ We have now shown that alignment within \pm 15 dioptres of straight at 3-6 months post-operatively is associated with a favourable outcome in childhood exotropia, and any child not achieving this alignment should be considered for further surgery. The use of stricter criteria of alignment within \pm 10 dioptres of straight or less strict criteria of alignment within \pm 20 dioptres of straight at 3-6 months post-operatively includes or excludes children inappropriately for consideration for further surgery.

Consecutive convergence following surgery for childhood exotropia has been of concern due to the potential for developing a monofixation syndrome with resultant amblyopia. ${ }^{11}$ However, the initial post-operative alignment is likely to become more divergent, ${ }^{15}$ and a moderate overcorrection at the initial post-operative examination has been shown to be associated with good alignment at 1 and 2 years following strabismus surgery. ${ }^{16}$ Binocularity may also be restored following surgery for consecutive esotropia. ${ }^{17}$ For these reasons the aim of strabismus surgery in childhood exotropia may include a small initial overcorrection, which differs from the surgical management of exotropia in adults. ${ }^{18}$

A consecutive esotropia was present in 16 of the 42 children $(38.1 \%)$ in our study at the first post-operative visit; 9 of these children had a consecutive esotropia of up to +10 dioptres, 6 children had a consecutive esotropia of between +10 and +20 dioptres, and 1 child had a consecutive esotropia of greater than +20 dioptres. This last child showed motor fusion pre-operatively, but had no evidence of binocular single vision post-operatively. There was evidence of binocular single vision in the other 15 children at final outcome; sensory fusion was present in 13 children and motor fusion in 2 children. No further surgery was undertaken for any of the children with consecutive esotropia.

In summary, a favourable outcome can be expected with surgery for all children with simulated and true distance exotropia, and for the majority of children with constant exotropia. The initial surgery should aim for a post-operative alignment within \pm 15 dioptres of straight. An initial post-operative consecutive esotropia was associated with a favourable outcome in all children without further surgery. A post-operative alignment within \pm 15 dioptres of straight at 3-6 months correlates well with the achievement of a favourable outcome, and any child not so aligned at this time should be considered for further surgery.

The authors are grateful to Helen Jones, University Department of Ophthalmology, Birmingham, for statistical advice.

Key words: Alignment, Amblyopia, Binocular single vision, Exotropia. Strabismus. 


\section{REFERENCES}

1. Mein J, Trimble R. Diagnosis and management of ocular motility disorders. 2nd ed. Oxford: Blackwell Scientific, 1991:227.

2. Von Noorden GK. Binocular vision and ocular motility. 4th ed. St Louis: CV Mosby, 1990:326-8.

3. Richard JM, Parks MM. Intermittent exotropia: surgical results in different age groups. Am J Ophthalmol 1983;90:1172-7.

4. Moore A. Refraction of infants and young children. In: Taylor D, Avetisov E, Baraitser M, et al., editors. Pediatric ophthalmology. Boston: Blackwell Scientific, 1990:65-70.

5. Willshaw HE, Keenan JM. Strabismus surgery in children: the prospects for binocular single vision. Eye 1991;5: 338-43.

6. Cooper J, Record CD. Suppression and retinal correspondence in intermittent exotropia. $\mathrm{Br} \mathrm{J}$ Ophthalmol 1986;70:673-6.

7. Richard JM, Parks MM. Intermittent exotropia: surgical results in different age groups. Ophthalmology 1993;90:1172-7.

8. Hardesty HH, Boynton JR, Keenan P. Treatment of intermittent exotropia. Arch Ophthalmol 1978;96:268-74.

9. Rubin SE, Nelson LB, Wagner RS, Simon JW, Catalano RA.
Infantile exotropia in healthy children. Ophthalmic Surg 1988;19:792-4.

10. Knapp P. Divergent deviations. In: Allen JH, editor. Strabismic ophthalmic symposium 11, St Louis: CV Mosby, 1958:354.

11. Pratt-Johnson JA, Barlow JM, Tillson G. Early surgery in intermittent exotropia. Am J Ophthalmol 1977;84:689-94.

12. Caltrider N, Jampolsky A. Overcorrecting minus lens therapy for treatment of intermittent exotropia. Ophthalmology 1983;90:1160-5.

13. Keenan JM, Willshaw HE. The outcome of strabismus surgery in childhood esotropia. Eye 1993;7:341-5.

14. Keenan JM, Willshaw HE. Outcome of strabismus surgery in congenital esotropia. Br J Ophthalmol 1992;76:342-5.

15. Raab EL, Parks MM. Recession of the lateral recti: early and late postoperative alignments. Arch Ophthalmol 1969;82: 203-8.

16. Scott WE, Keech R, Mash AJ. The postoperative results and stability of exodeviations. Arch Ophthalmol 1981;99: 1814-8

17. Smoot CN, Simon JW, Nelson LB. Binocularity following surgery for secondary esotropia in childhood. Br J Ophthalmol 1990;74:155-7.

18. Schlossman A, Muchnick RS, Stern KS. The surgical management of intermittent exotropia in adults. Ophthalmology 1983;90:1166-71. 